\title{
Growth and Activation of an Amorphous Molybdenum Sulfide Hydrogen Evolving Catalyst
}

\author{
Heron Vrubel and Xile $\mathrm{Hu}^{*}$
}

Laboratory of Inorganic Synthesis and Catalysis, Institute of Chemical Sciences and Engineering, Ecole Polytechnique Fédérale de Lausanne (EPFL), ISIC-LSCI, BCH 3305, Lausanne, CH 1015, Switzerland

\section{Supporting Information}

ABSTRACT: Amorphous molybdenum sulfide films, prepared by electrodeposition, are a class of highly active catalysts for hydrogen evolution. The growth mechanism of the films and the true active species were unclear. Herein, we report a study of the growth and activation of these films using Electrochemical Quartz Crystal Microbalance (EQCM) and X-ray photoelectron spectroscopy (XPS). Three processes, including oxidative deposition, reductive corrosion, and reductive deposition, are occurring during the growth of a molybdenum sulfide film. Deposition method, precursor concentration, and potential window are among the factors influencing the film growth. Regardless of deposition methods, all films

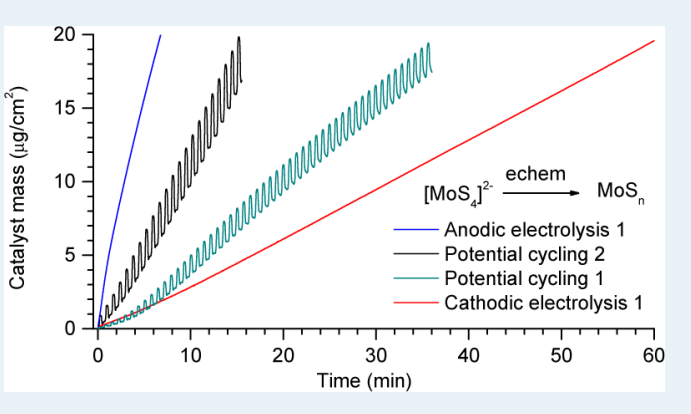
exhibit similar catalytic activity on a per mass base. Potentiostatic oxidation (anodic electrolysis) is the method for fastest film growth; it produces a $\mathrm{MoS}_{3}$ film precatalyst which can be electrochemically activated. The activity of the $\mathrm{MoS}_{3}$ precatalyst scales with catalyst loading; at a loading of $0.2 \mathrm{mg} / \mathrm{cm}^{2}$, the current density is 20 $\mathrm{mA} / \mathrm{cm}^{2}$ at an overpotential of $170 \mathrm{mV}$. Films differently deposited have different initial compositions, but the active catalysts in all films are the same $\mathrm{MoS}_{2+x}$ species, whose XPS characteristics are distinct from those of crystalline $\mathrm{MoS}_{2}$. The activation process of a $\mathrm{MoS}_{3}$ film precatalyst involves a reductive removal of slightly less than one equivalent of sulfide to form $\mathrm{MoS}_{2+x}$.

KEYWORDS: hydrogen evolution, molybdenum sulfide, electrocatalysis, electrochemical quartz crystal microbalance,

$X$-ray photoelectron spectroscopy, thin films

\section{INTRODUCTION}

Renewable energy sources such as solar and wind are intermittent, so they require storage methods to offset the mismatch between energy production and consumption. Among various energy storage methods, storage in the form of chemical fuels is attractive thanks to their high energy density and potentially low cost. ${ }^{1,2}$ Consequently, the water splitting reaction has drawn much attention, as it allows the storage of electric and photoelectric energy in hydrogen, a clean energy carrier. ${ }^{3,4}$ The hydrogen evolution reaction (HER), where hydrogen is produced by reduction of protons, is an essential half reaction of water splitting. This reaction requires a catalyst to proceed in a rate that is useful for energy storage. Platinum is a very active catalyst; it is however too expensive and rare to fulfill a significant portion of the demand in energy storage. A great deal of research is carried out to develop nonprecious catalysts for HER. ${ }^{5-10}$

Molybdenum sulfides have emerged as a promising class of nonprecious catalysts for HER under acidic conditions. ${ }^{11,12}$ Bulk $\mathrm{MoS}_{2}$ only has modest activity and draws little attention since it was first studied in the 1970 s. ${ }^{13,14}$ In two pioneering studies, the edge sites of $\mathrm{MoS}_{2}$ were shown as the active sites for HER; ${ }^{15,16} \mathrm{MoS}_{2}$ nanoparticles rich in edge sites were highly active for HER. ${ }^{16}$ These studies have inspired a large body of follow-up work that aims at improving the activity of $\mathrm{MoS}_{2}$ nanoparticles by nanostructuring and by hybridization with gold, graphene, mesoporous carbon, or carbon fiber. ${ }^{17-26}$

Our group has discovered that amorphous molybdenum sulfides (Mo-S) are active HER catalysts. ${ }^{27-29}$ The activity of amorphous Mo-S compares favorably with some of the most active $\mathrm{MoS}_{2}$ nanoparticles. The most important improvement, however, is that these amorphous Mo-S catalysts are produced in a solution process under mild conditions, whereas $\mathrm{MoS}_{2}$ nanoparticles are mostly produced by high-temperature sulfidation reactions or hydrothermal reactions. Since many photocathodes are unstable or inconvenient substrates for hightemperature or hydrothermal reactions, the solution-processable amorphous molybdenum sulfide species are more suitable catalysts to be combined with a photocathode for photoelectrochemical hydrogen production. Indeed, an amorphous $\mathrm{Mo}-\mathrm{S}$ film was deposited onto a $\mathrm{TiO}_{2}$-protected $\mathrm{n}^{+}-\mathrm{p}-\mathrm{Si}$ photocathode. ${ }^{30}$ The resulting photoactive material has an onset potential of $0.33 \mathrm{~V}$ vs NHE for hydrogen evolution in acidic solutions.

The high activity of amorphous Mo-S catalysts and their applicability for photoelectrochemical hydrogen production provide incentives for a deep understanding of the formation

Received: June 12, 2013

Revised: July 20, 2013

Published: July 22, 2013 
and properties of these catalysts. Previously, we developed the procedure to deposit amorphous $\mathrm{MoS}_{3}$ films by consecutive potential cycling. While this procedure is simple, efficient, and amenable to photodeposition, the growth mechanism of the film was unclear. Herein, we present an Electrochemical Quartz Crystal Microbalance (EQCM) study of the deposition of $\mathrm{MoS}_{3}$ films. The study reveals a potential-dependent growth of the films and establishes a growth-activity relationship. On the basis of this study, an improved procedure for catalyst deposition is developed. We also describe the study of the activation process that converts the as-deposited $\mathrm{MoS}_{3}$ precatalyst to the active $\mathrm{MoS}_{2+x}$ catalyst using EQCM and Xray photoelectron spectroscopy (XPS). The activation is associated with a loss of near one molecule of $S$ and a significant change in the S $2 \mathrm{p}$ XPS spectra.

\section{RESULTS AND DISCUSSION}

1. Growth of an Amorphous $\mathrm{MoS}_{3}$ Film. 1.1. Cyclic Voltammogram. Previously, we found that a $\mathrm{MoS}_{3}$ film could be electrodeposited from an aqueous solution of $\left(\mathrm{NH}_{4}\right)_{2}\left[\mathrm{MoS}_{4}\right]^{29}$ In a typical procedure, the potential of a conductive electrode is cycled repetitively from 0.7 to $-0.4 \mathrm{~V}$ vs $\mathrm{RHE}(0.1$ to $-1.0 \mathrm{~V}$ vs $\mathrm{Ag} / \mathrm{AgCl}$ at $\mathrm{pH}=6.6$; unless otherwise specified, all potentials are referred to RHE) in a solution containing $\left(\mathrm{NH}_{4}\right)_{2}\left[\mathrm{MoS}_{4}\right]$ as the source of $\mathrm{MoS}_{3}$ and $\mathrm{NaClO}_{4}$ as the supporting electrolyte. Figure 1 shows the cyclic

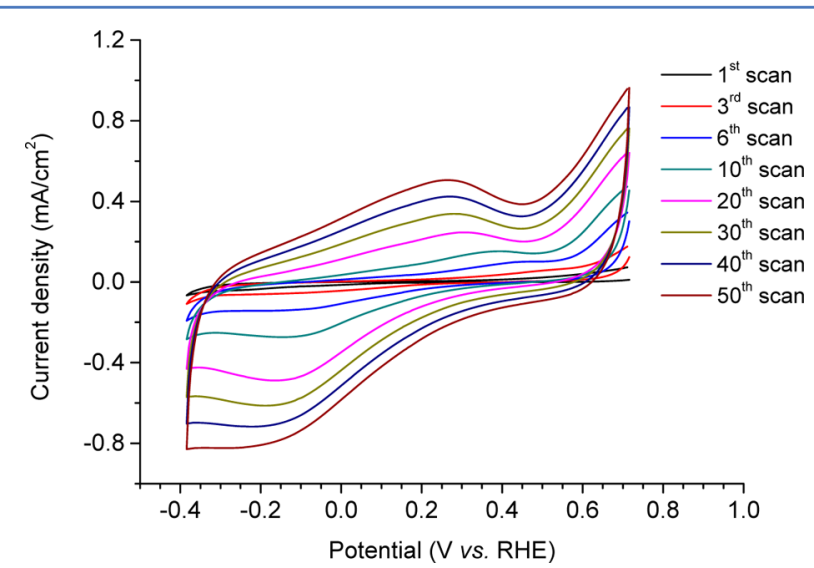

Figure 1. Selected cyclic voltammograms during the deposition of a molybdenum sulfide film using the potential cycling method. Conditions: glassy carbon substrate, $\mathrm{NaClO}_{4}$ electrolyte $(0.1 \mathrm{M})$, scan rate $50 \mathrm{mV} / \mathrm{s}, 2 \mathrm{mM}\left(\mathrm{NH}_{4}\right)_{2}\left[\mathrm{MoS}_{4}\right]$.

voltammograms of this process. Initially, the currents are small and featureless. After several scans, a number of features become evident. An oxidation peak is observed at $0.3 \mathrm{~V}$, and a reduction peak is observed at $-0.10 \mathrm{~V}$. In addition, a significant oxidative current is observed at the positive limit of the potential window, i.e., around 0.5 to $0.7 \mathrm{~V}$; a negative current grows with time at the negative limit of the potential window, around -0.3 to $-0.4 \mathrm{~V}$. The cyclic voltammograms are similar with different substrates such as indium tin oxide (ITO), fluorine-doped tin oxide (FTO), and glassy carbon. The evolution of cyclic voltammograms is concomitant with film growth, so it can be used as a first indication for a successful deposition of catalyst. The deposition of $\mathrm{MoS}_{3}$ film therefore appears to be substrate-independent.

1.2. Mass Change during Deposition of a $\mathrm{MoS}_{3}$ Film. While the cyclic voltammograms indicate redox reactions associated with film deposition, the nature of these reactions is unclear. The amount of deposited catalyst is often too small to be accurately determined by ex situ elemental analysis measurements (e.g., by ICP-AES), so a correlation between the current of deposition and mass of the film is hard to establish. Since EQCM is a powerful tool to study electrodeposition and to measure a small change of mass, we decided to investigate the growth of $\mathrm{MoS}_{3}$ film by EQCM.

The deposition under previously reported conditions was first examined. The potential window was from 0.7 to $-0.4 \mathrm{~V}$ vs RHE. After some exploratory trials, we set the starting point of measurement at $0.3 \mathrm{~V}$, where no change of mass takes place (see below). From this point, the electrode was first polarized positively and then cyclically scanned from $0.7 \mathrm{~V}$ to $-0.4 \mathrm{~V}$. Figure 2 shows the change of mass during the deposition

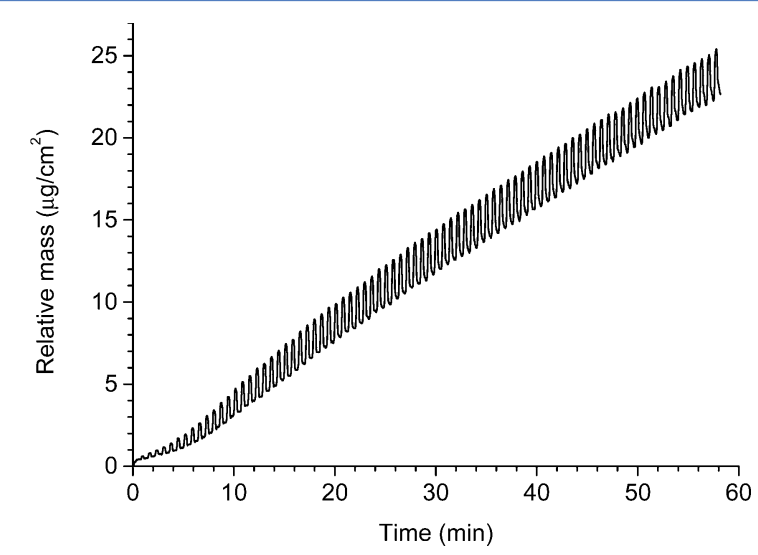

Figure 2. The change of mass during the deposition of a molybdenum sulfide film using the potential cycling method. Conditions: Au substrate, $\mathrm{NaClO}_{4}$ electrolyte $(0.1 \mathrm{M})$, scan rate $50 \mathrm{mV} / \mathrm{s}, 2 \mathrm{mM}$ $\left(\mathrm{NH}_{4}\right)_{2}\left[\mathrm{MoS}_{4}\right]$.

process. A repetitive pattern of mass increase followed by immediate mass decrease is observed. This indicates a sequence of consecutive deposition and corrosion. The total mass increases exponentially during the first scanning cycles and then linearly after about 10 scanning cycles (Figure 3 ). About $25 \mu \mathrm{g} / \mathrm{cm}^{2}$ of $\mathrm{MoS}_{3}$ film was deposited after 50 cycles in this case.

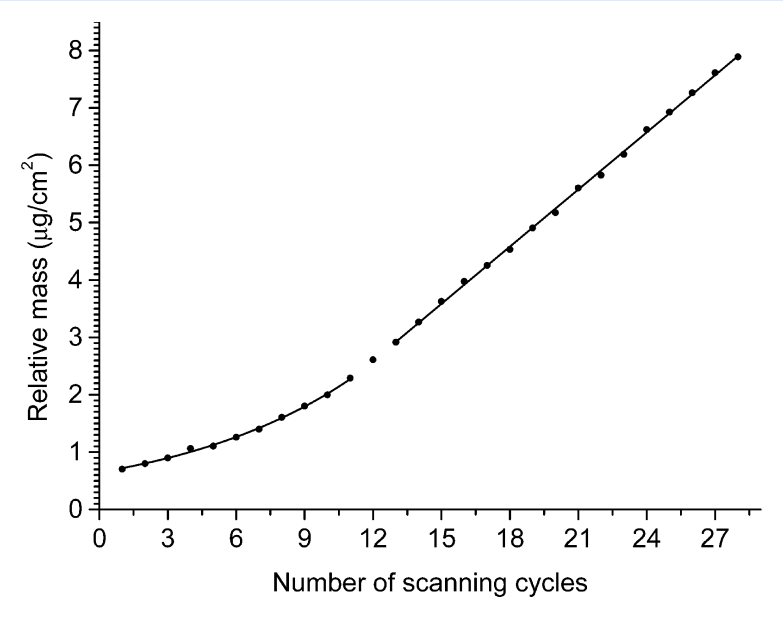

Figure 3. Scan-number dependence of the mass of a molybdenum sulfide film. 
By setting a high gain on the frequency-to-voltage converter of EQCM, we were able to measure the mass changes during a single scanning cycle. Figure 4 shows the mass change during

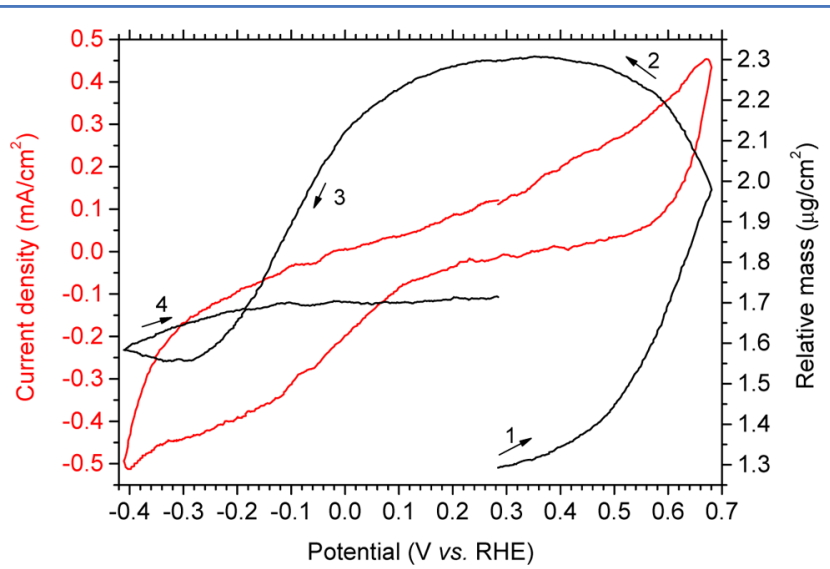

Figure 4. The evolution of current (red line) and film mass (black line) during the sixth potential cycle. Arrows and numbers indicate the direction of potential scanning; the starting point is at about $0.3 \mathrm{~V}$. Conditions: $\mathrm{Au}$ substrate, $\mathrm{NaClO}_{4}$ electrolyte $(0.1 \mathrm{M})$, scan rate 50 $\mathrm{mV} / \mathrm{s}, 2 \mathrm{mM}\left(\mathrm{NH}_{4}\right)_{2}\left[\mathrm{MoS}_{4}\right]$.

the sixth deposition cycle. When scanned positively from $0.3 \mathrm{~V}$, the deposition (mass increase) starts shortly after (arrow 1) and continues until the potential reaches $0.4 \mathrm{~V}$ in the following negative scan (arrow 2). From 0.4 to $0.2 \mathrm{~V}$, the mass is constant. A corrosion process then causes the mass to decrease at 0.2 to $-0.25 \mathrm{~V}$ (arrow 3). At the latter potential, a new deposition process starts. This deposition continues until the potential is reversed to $-0.2 \mathrm{~V}$ in the following positive scan. After that, the mass stays constant until the end of this scanning cycle $(0.3 \mathrm{~V})$. The deposition is most rapid between 0.5 and 0.7 $\mathrm{V}$, and the corrosion is most rapid between 0.1 and $-0.2 \mathrm{~V}$. The mass increase by oxidative deposition (at 0.4 to $0.7 \mathrm{~V}$ ) is about 10 times that of the mass increase by reductive deposition (at -0.3 to $-0.4 \mathrm{~V}$ ). The corrosion process removes about $70 \%$ of the mass increase from oxidative deposition. The absence of corrosion at -0.2 to $0.3 \mathrm{~V}$ in the final part of the scanning cycle indicates that the partial corrosion of the species formed from oxidative deposition has finished in the preceding scan, and the species formed from reductive deposition is not subject to corrosion.

As the film grows thicker, the reductive deposition process (at -0.3 to $-0.4 \mathrm{~V}$ ) is no longer visible, probably because it coincides with the reductive corrosion at the same potentials, resulting in no obvious mass change. Figure S4 of the Supporting Information shows the mass change during the 16th scanning cycle, which reveals a single oxidative deposition $(0.4$ to $0.7 \mathrm{~V})$ and a broad reductive corrosion $(0.2$ to $-0.4 \mathrm{~V})$.

1.3. Explanation of Cyclic Voltammogram. The potentialdependent mass change during deposition of a $\mathrm{MoS}_{3}$ film provides clues to explain the cyclic voltammograms in Figure 1. The oxidation event at 0.3 to $0.7 \mathrm{~V}$ is associated with the oxidative deposition, while the reduction event from 0.1 to $-0.2 \mathrm{~V}$ is associated with the reductive corrosion. The reduction at $-0.2 \mathrm{~V}$ to -0.4 reflects both the reductive corrosion and deposition processes. The broad and pronounced oxidation peak, centered at $0.3 \mathrm{~V}$, is not associated with deposition or corrosion. It is therefore unrelated to film growth. We suspect that this feature is due to a significant capacitive current of the porous film. ${ }^{28}$

1.4. Chemical Reactions Related to Film Growth and Corrosion. The above EQCM study establishes that a $\mathrm{MoS}_{3}$ film is grown by oxidation of $\left[\mathrm{MoS}_{4}\right]^{2-}$ ions at 0.3 to $0.7 \mathrm{~V}$ and is corroded by reduction at 0.15 to $-0.4 \mathrm{~V}$. This supports our earlier proposal that a $\mathrm{MoS}_{3}$ film is formed through the following reaction: ${ }^{31}$

$$
\left[\mathrm{MoS}_{4}\right]^{2-} \rightarrow \mathrm{MoS}_{3}+\frac{1}{8} \mathrm{~S}_{8}+2 \mathrm{e}
$$

This reaction produces not only $\mathrm{MoS}_{3}$ but also elemental S.

The corrosion of $\mathrm{MoS}_{3}$ consumes about $70 \%$ of the newly deposited film. A reduction of $\mathrm{MoS}_{3}$ to form $\mathrm{MoS}_{2}$ will not amount to the same weight loss. The corrosion is more probably due to the reverse reaction of eq 1 :

$$
\mathrm{MoS}_{3}+\frac{1}{8} \mathrm{~S}_{8}+2 \mathrm{e} \rightarrow\left[\mathrm{MoS}_{4}\right]^{2-}
$$

Reduction of $\mathrm{MoS}_{3}$ by other reactions is also possible. In any case, eqs 1 and 2 are not fully reversible, suggesting that the relative rates of deposition and corrosion might be controlled by varying electrodeposition conditions. This is indeed achieved (see section 1.5).

The reductive deposition, observed at -0.2 to $-0.4 \mathrm{~V}$ in the initial scans, is attributed to the following reaction: ${ }^{32}$

$$
\left[\mathrm{MoS}_{4}\right]^{2-}+2 \mathrm{H}_{2} \mathrm{O}+2 \mathrm{e} \rightarrow \mathrm{MoS}_{2}+2 \mathrm{HS}^{-}+2 \mathrm{HO}^{-}
$$

This reaction produces "amorphous $\mathrm{MoS}_{2}$ " (see sections 2.2 and 2.3 for a discussion of the term "amorphous $\mathrm{MoS}_{2}$ ") which is mixed with $\mathrm{MoS}_{3}$ in the film. Additionally, the hydrosulfide and hydroxide ligands may coordinate to molybdenum. These anionic groups might undergo further transformation to various oxo and sulfido species.

1.5. Optimization of Film Deposition. EQCM was next applied to monitor film growth under several other deposition conditions, in order to find better procedures. Previously, we found that thicker films were produced when the concentrations of $\left[\mathrm{MoS}_{4}\right]^{2-}$ in the deposition bath were higher. ${ }^{29}$ This concentration-dependent film growth was quantified by EQCM. Figure 5 shows the changes of the mass of the films

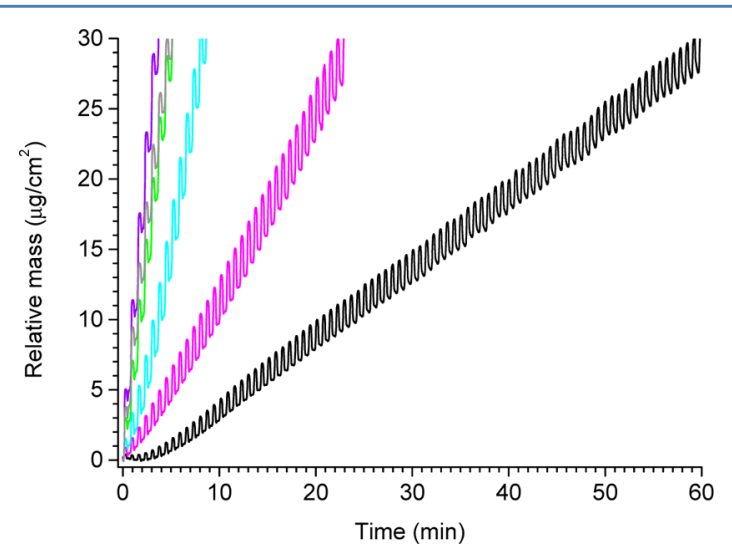

Figure 5. Concentration dependence for the electrodeposition of $\mathrm{MoS}_{3}$ by consecutive cyclic voltammetry. $\left[\mathrm{MoS}_{4}\right]^{2-}$ are as follows: 1.7 $\mathrm{mM}$ (black), $3.9 \mathrm{mM}$ (magenta), $7.9 \mathrm{mM}$ (cyan), $16.1 \mathrm{mM}$ (green), $23.6 \mathrm{mM}$ (gray), $31.3 \mathrm{mM}$ (purple). Au substrate; $\mathrm{NaClO}_{4}$ electrolyte $(0.1 \mathrm{M})$; scan rate $50 \mathrm{mV} / \mathrm{s}$. 
deposited from five solutions with a same concentration of electrolyte $\left(0.1 \mathrm{M} \mathrm{NaClO}_{4}\right)$ but a different concentration of $\left[\mathrm{MoS}_{4}\right]^{2-}$ (from $1.6 \mathrm{mM}$ to $31 \mathrm{mM}$ ). The higher the concentration, the faster the film grows. Thus, it took $60 \mathrm{~min}$ to deposit a film of $30 \mu \mathrm{g} / \mathrm{cm}^{2}$ from a $1.6 \mathrm{mM}$ solution of $\left[\mathrm{MoS}_{4}\right]^{2-}$, but less than $4 \mathrm{~min}$ to deposit the same film from a $31 \mathrm{mM}$ solution of $\left[\mathrm{MoS}_{4}\right]^{2-}$. The ratio of corrosion/ deposition in each scanning cycle also decreases when the concentration of $\left[\mathrm{MoS}_{4}\right]^{2-}$ increases. At higher $\left[\mathrm{MoS}_{4}\right]^{2-}$ concentrations $(>10 \mathrm{mM})$, the magnitude of corrosion is less than $10 \%$ of that of deposition.

The potential window of deposition was then varied. Figure 6 shows the growth of film in four different potential windows.

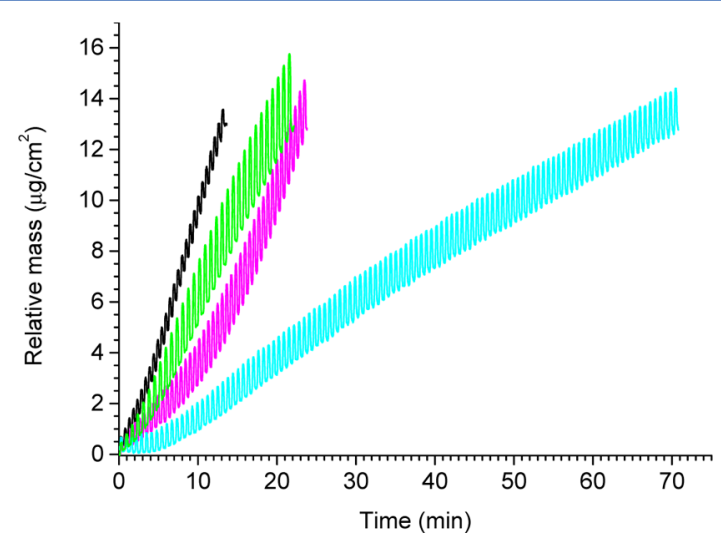

Figure 6. The time-dependent growth of $\mathrm{MoS}_{3}$ films deposited by cyclic voltammetry at different potential windows: 0.7 to $-0.1 \mathrm{~V}$ (black), 0.7 to $-0.2 \mathrm{~V}$ (magenta), 0.7 to $-0.3 \mathrm{~V}$ (cyan), and 0.7 to $-0.4 \mathrm{~V}$ vs $\mathrm{RHE}$ (green). Conditions: Au substrate, $\mathrm{NaClO}_{4}$ electrolyte $(0.1 \mathrm{M})$, scan rate $50 \mathrm{mV} / \mathrm{s}, 2 \mathrm{mM}\left(\mathrm{NH}_{4}\right)_{2}\left[\mathrm{MoS}_{4}\right]$.

The negative limit of the potential window has a significant effect on film growth. When this limit was changed from -0.1 $\mathrm{V}$ to $-0.3 \mathrm{~V}$, the corrosion was more severe, and the film grew much slower. To deposit a film of $13 \mu \mathrm{g} / \mathrm{cm}^{2}$, scanning from 0.7 to $-0.3 \mathrm{~V}$ was 6 times slower than scanning from 0.7 to $-0.1 \mathrm{~V}$. Interestingly, the growth of the film increased when changing the negative potential limit from -0.3 to $-0.4 \mathrm{~V}$. This is probably due to the deposition of a substantial amount of “amorphous $\mathrm{MoS}_{2}$ ” by eq 3 .

According to eqs 1 and 3, amorphous $\mathrm{MoS}_{3}$ and $\mathrm{MoS}_{2}$ films can be deposited at a constant potential, without potential cycling. We deposited a film by anodic electrolysis at $0.7 \mathrm{~V}$ $\left(\mathrm{MoS}_{3}-\mathrm{AE}\right)$ and a film by cathodic electrolysis at $-0.4 \mathrm{~V}$ $\left(\mathrm{MoS}_{2}-\mathrm{CE}\right)$. EQCM was used to monitor the growth of these two films (Figure 7). Only deposition but not corrosion was observed. Anodic electrolysis at $0.7 \mathrm{~V}$ is more efficient than potential cycling between $0.7 \mathrm{~V}$ and $-0.4 \mathrm{~V}$, producing a film of same mass in $1 / 4$ of the time. Film growth by cathodic electrolysis at $-0.4 \mathrm{~V}$, however, is the slowest.

The results in this section show that it is possible to control the speed of film growth by varying the deposition conditions such as precursor concentration, potential window, and even deposition technique. If the method of potential cycling is employed, then a higher precursor concentration and a lower negative limit of the potential window favor film growth over corrosion. If other electrodeposition techniques are considered, then anodic deposition at a sufficiently positive potential for eq 1 appears most efficient.

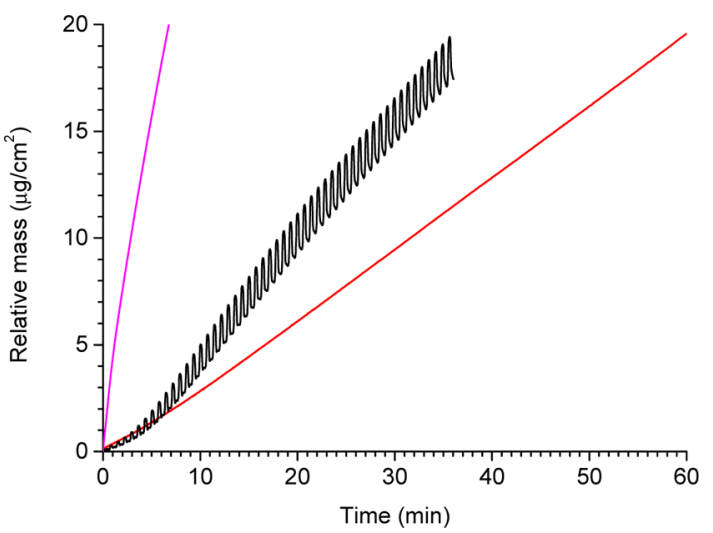

Figure 7. Comparison of the growth rate of molybdenum sulfide films using different deposition methods: anodic electrolysis at $0.7 \mathrm{~V}$ (magenta), potential cycling from 0.7 to $-0.4 \mathrm{~V}$ (black), and cathodic electrolysis at $-0.4 \mathrm{~V}(\mathrm{red})$. Au substrate, $\mathrm{NaClO}_{4}$ electrolyte $(0.1 \mathrm{M})$, $\left[\mathrm{MoS}_{4}\right]^{2-}=2 \mathrm{mM}$, scan rate $50 \mathrm{mV} / \mathrm{s}$ for the deposition by potential cycling.

1.6. Activity Comparison. As the growth rate of various molybdenum films has been determined by EQCM, it is possible to deposit films with the same mass by different methods. This allows the comparison of catalytic activity on a per weight basis. For this purpose, three films were deposited on glassy carbon, all with a loading of $15 \mu \mathrm{g} \cdot \mathrm{cm}^{-2}$. The film $\mathrm{MoS}_{3}-\mathrm{CV}$ was prepared by 40 consecutive scans between $0.7 \mathrm{~V}$ and $-0.4 \mathrm{~V}$. The film $\mathrm{MoS}_{3}-\mathrm{AE}$ was prepared by electrolysis at $0.7 \mathrm{~V}$ for $4.8 \mathrm{~min}$. The film $\mathrm{MoS}_{2}-\mathrm{CE}$ was prepared by electrolysis at $-0.4 \mathrm{~V}$ for $48 \mathrm{~min}$. Figure 8 shows the 10th (stable) polarization curves of these catalysts in a $1.0 \mathrm{M}$ solution of $\mathrm{H}_{2} \mathrm{SO}_{4}$.

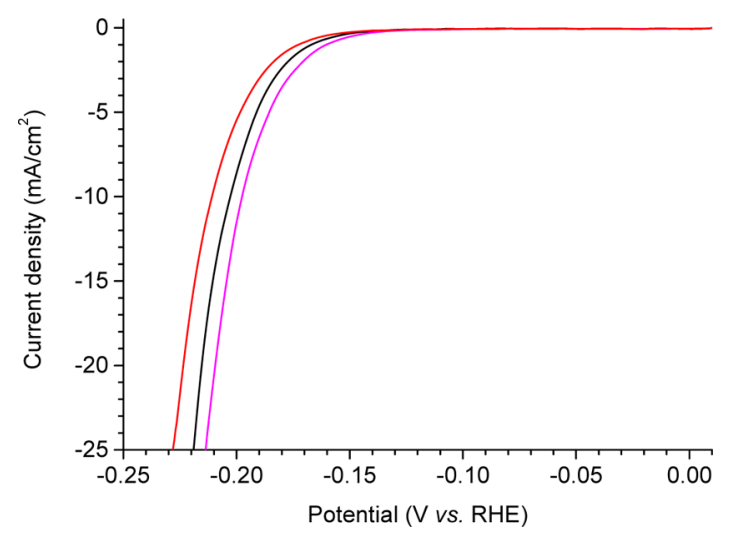

Figure 8. Polarization curves in $1.0 \mathrm{M} \mathrm{H}_{2} \mathrm{SO}_{4}$ for amorphous molybdenum sulfide films deposited using different methods; glassy carbon electrode; loading, $15 \mu \mathrm{g} \cdot \mathrm{cm}^{-2}$; scan rate, $5 \mathrm{mV} \cdot \mathrm{s}^{-1}$. CV (black), AE (magenta), CE (red).

While the film prepared by anodic electrolysis is slightly more active, to a first approximation, the activity of the three films is similar. We reported earlier an analogous comparison that indicated that the $\mathrm{MoS}_{2}$-CE film was significantly less active than $\mathrm{MoS}_{3}-\mathrm{CV}$ and $\mathrm{MoS}_{3}-\mathrm{AE}$ films. ${ }^{29}$ That study did not consider a possible difference in catalyst loading. The current EQCM study shows that the growth of $\mathrm{MoS}_{2}$-CE film is much slower than the other two films; thus, the previously reported inferior activity of the $\mathrm{MoS}_{2}$-CE film is mostly due to its lower catalyst loading. 
Considering the activity and growth rate, anodic deposition at a constant potential seems to be the most efficient method in producing a molybdenum sulfide film. This method was chosen for the measurements in sections 1.7 and 1.8.

1.7. Correlation between Charge and Mass. It is impractical to determine the mass of a molybdenum sulfide film using EQCM every time. If a correlation can be established between the amount of charge passed during electrodeposition and the mass of the deposited film, the latter can be simply deduced from the former, which is readily obtained from the electrochemical data. EQCM was used to build this correlation for a $\mathrm{MoS}_{3} \mathrm{AE}$ film deposited by anodic electrolysis at $0.7 \mathrm{~V}$. The mass of the film exhibits a nearly linear dependence on the amount of charge (Figure 9, black line). The mass is slightly

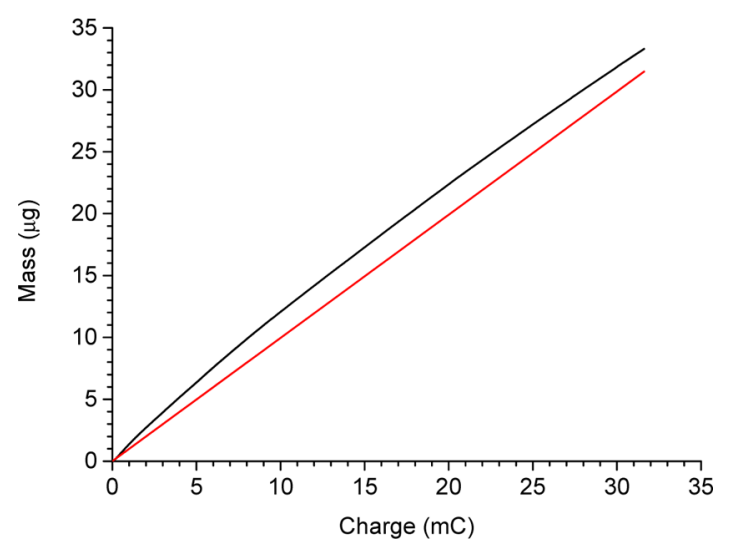

Figure 9. Correlation of the mass of the film and the charge passed during the electrodeposition of a $\mathrm{MoS}_{3}-\mathrm{AE}$ film. Experimental data (black), expected theoretical mass (red) if two electrons are used for the formation of pure $\mathrm{MoS}_{3}$.

higher than expected for $\mathrm{MoS}_{3}$, assuming a quantitative Faradaic yield for eq 1 (Figure 9, red line). The discrepancy is attributed to the side product, elemental $\mathrm{S}$, some of which is trapped in the $\mathrm{MoS}_{3}$ film (see above).

1.8. Benchmarking. The preceding work enables us to control the precise mass of a $\mathrm{MoS}_{3}$ film in a given geometric area. In our earlier work, only the activity of thin films with a loading below $30 \mu \mathrm{g} \cdot \mathrm{cm}^{-2}$ was measured. We then deposited films with a much higher loading. The conventional glassy carbon electrode contains an insulating plastic layer around the carbon core; when a $\mathrm{MoS}_{3}$ film grows thicker, some deposition on the insulator was seen, which would complicate analysis. Thus, we used flat Au electrodes as the substrates; on such a flat electrode, a loading of up to $300 \mu \mathrm{g} \cdot \mathrm{cm}^{-2}$ can be achieved in a concentrated solution of $\left[\mathrm{MoS}_{4}\right]^{2-}(30 \mathrm{mM})$. Even higher catalyst loading will necessitate a porous electrode such as nickel foam and carbon fiber. ${ }^{22,23}$

Figure 10 shows the steady-state polarization curves of four $\mathrm{MoS}_{3}$ films with incremental loadings from 26 to $198 \mu \mathrm{g} \cdot \mathrm{cm}^{-2}$. These polarization curves show the benchmark activity of $\mathrm{MoS}_{3}$ films, as both the apparent geometric area and the catalyst loading are known. The catalytic activity scales with catalyst loading. With a catalyst loading of ca. $200 \mu \mathrm{g} \cdot \mathrm{cm}^{-2}$, an overpotential of ca. $170 \mathrm{mV}$ is required to achieve a current density of $20 \mathrm{~mA} / \mathrm{cm}^{2}$. This specific activity is high compared to other state of the art nonprecious HER catalysts in acidic solutions. ${ }^{9}$

2. Activation of $\mathrm{MoS}_{3}$ Precatalyst. 2.1. Composition of Various Molybdenum Sulfide Films. According to sections 1.4

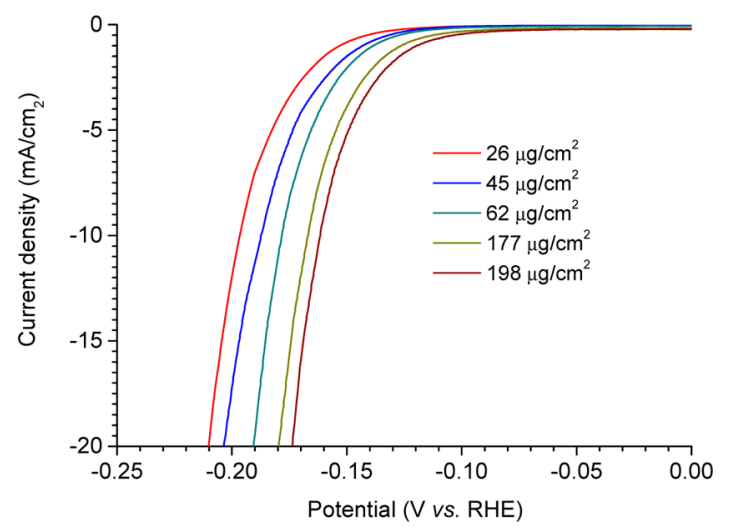

Figure 10. Stable (10th) polarization curves in $1.0 \mathrm{M} \mathrm{H}_{2} \mathrm{SO}_{4}$ for $\mathrm{MoS}_{3}$ films at different loadings; Au substrate; scan rate, $5 \mathrm{mV} \cdot \mathrm{s}^{-1}$.

and 1.5, molybdenum sulfide films of different compositions might be produced depending on the methods of electrodeposition. A potentiostatic electrolysis at $0.7 \mathrm{~V}$ produces a film of $\mathrm{MoS}_{3}$ plus some elemental S $\left(\mathrm{MoS}_{3}-\mathrm{AE}\right)$; a potentiostatic electrolysis at $-0.4 \mathrm{~V}$ produces a film of "amorphous $\mathrm{MoS}_{2}$ " plus some hydroxide and hydrosulfide $\left(\mathrm{MoS}_{2}-\mathrm{CE}\right)$. Potential cycling produces films with less regular compositions, since the deposition and corrosion of molybdenum sulfides are potential dependent. A repetitive potential cycling from 0.7 to $-0.4 \mathrm{~V}$ produces a mixture of $\mathrm{MoS}_{3}$ and $\mathrm{MoS}_{2}$, likely more $\mathrm{MoS}_{3}$ than $\mathrm{MoS}_{2}$, but without elemental $\mathrm{S}$, which is consumed during corrosion. Potential cycling from -0.4 to $0.7 \mathrm{~V}$, on the other hand, may produce the same mixture but with a higher proportion of $\mathrm{MoS}_{2}$. The variance in composition is largest on the outer layers of the films which are deposited in the last scanning cycle. Because X-ray photoelectron spectroscopy (XPS) only measures atoms and ions in these outer layers, the previously reported remarkable difference in the XPS spectra of two films, both deposited by potential cycling but one from 0.7 to $-0.4 \mathrm{~V}$ and the other from -0.4 to $0.7 \mathrm{~V}$, can now be understood.

Our earlier fitting of the S 2p XPS spectra revealed dissimilar sulfide species in molybdenum sulfide films. ${ }^{29}$ No fitting was done either on Mo 3d spectra or on S 2s spectra. To make the interpretation of XPS data more comparable to the findings of the EQCM study, we fit the Mo and S XPS data using a more rigorous procedure (higher resolution of data due to longer measurement time; fix of spin-orbit splitting energy and full width at half-maximum; calibration of binding energy by an internal standard for each measurement).

The XPS data of commercial $\mathrm{MoS}_{2}$ microcrystals were used as a reference (Figure 11). The Mo $3 \mathrm{~d}$ spectrum is dominated by a doublet with a Mo $3 \mathrm{~d}_{5 / 2}$ binding energy of $229.5 \mathrm{eV}$. This doublet is attributed to the $\mathrm{Mo}^{\mathrm{IV}}$ ion in $\mathrm{MoS}_{2}$. A small doublet with a Mo $3 \mathrm{~d}_{5 / 2}$ binding energy of $232.7 \mathrm{eV}$ is also visible. Such a binding energy is indicative of a $\mathrm{Mo}^{\mathrm{VI}}$ ion, as in $\mathrm{MoO}_{3}{ }^{33,34}$ The amount of $\mathrm{Mo}^{\mathrm{VI}}$ ion is about $4 \%$ of the total Mo ions, which suggests that crystalline $\mathrm{MoS}_{2}$ is quite resistant to aerobic oxidation. Next to the Mo $3 \mathrm{~d}$ doublets, a singlet corresponding to the $S 2$ s peak is seen. The binding energy of the latter is $226.7 \mathrm{eV}$. The S 2 p spectrum shows a single doublet with a $S$ $2 \mathrm{p}_{3 / 2}$ energy of $162.4 \mathrm{eV}$, attributable to the sulfide $\left(\mathrm{S}^{2-}\right)$ ligand in $\mathrm{MoS}_{2}$. The Mo/S ratio is 1:1.9. The XPS data of $\mathrm{MoS}_{2}$ were used to set the energy difference between the Mo $3 \mathrm{~d}_{3 / 2}$ and the Mo $3 \mathrm{~d}_{5 / 2}$ states $(3.14 \mathrm{eV})$, and between the $S 2 \mathrm{p}_{1 / 2}$ and the $S$ $2 \mathrm{p}_{3 / 2}$ states $(1.18 \mathrm{eV})$ for further data fitting. This is reasonable 

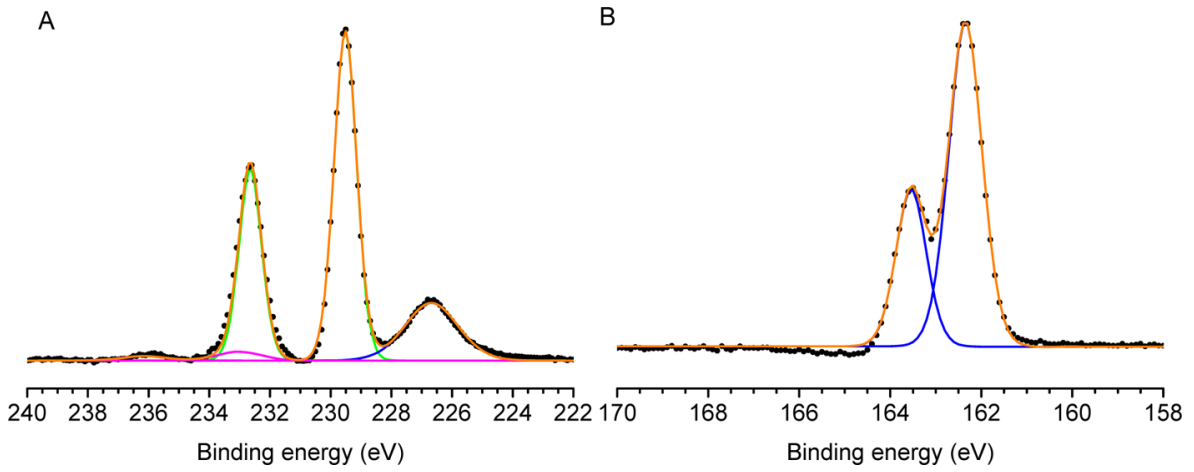

Figure 11. XPS spectra of $\mathrm{MoS}_{2}$ microcrystals. (A) Mo 3d region, experimental data (…), fitting envelope (gold), $\mathrm{MoS}_{2}\left(\right.$ green), $\mathrm{MoO}_{3}$ (magenta), $\mathrm{S}^{2-} 2 \mathrm{~s}$ (blue). (B) S 2p region, experimental data (…), fitting envelope (gold), $\mathrm{MoS}_{2}$ (blue). fwhm: Mo (3d), $1 \mathrm{eV} ; \mathrm{S}(2 \mathrm{p}), 0.8 \mathrm{eV} ; \mathrm{S}(2 \mathrm{~s}), 2.1 \mathrm{eV}$.

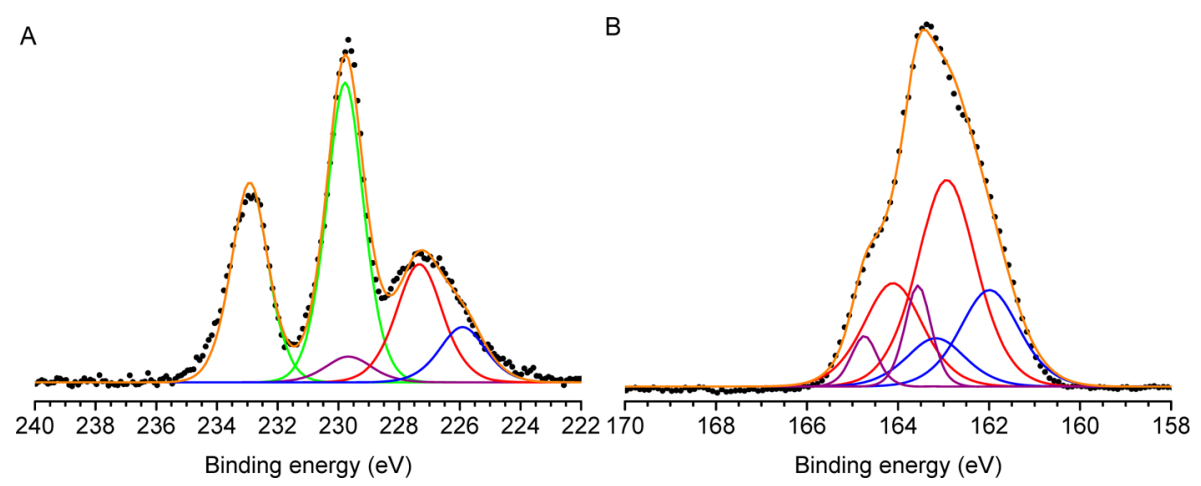

Figure 12. XPS spectra for $\mathrm{MoS}_{3}$-AE. (A) Mo $3 \mathrm{~d}$ region, experimental data (…), fitting envelope (gold), $\mathrm{MoS}_{3}\left(\right.$ green), $\mathrm{S}^{0} 2 \mathrm{~s}$ (purple), $\mathrm{S}_{2}{ }^{2-} 2 \mathrm{~s}$ (red), $S^{2-}, 2$ (blue). (B) $S$ 2p region, experimental data (…), fitting envelope (gold), $S^{0}$ (purple), $S_{2}{ }^{2-}$ (red), $S^{2-}$ (blue). fwhm: Mo (3d), $1.4 \mathrm{eV}$; $\mathrm{S}^{2-}$ and $\mathrm{S}_{2}{ }^{2-}(2 \mathrm{p}), 1.4 \mathrm{eV} ; \mathrm{S}^{2-}$ and $\mathrm{S}_{2}^{2-}(2 \mathrm{~s}), 3 \mathrm{eV} ; \mathrm{S}^{0}(2 \mathrm{p}), 0.7 \mathrm{eV} ; \mathrm{S}^{0}(2 \mathrm{~s}), 1.8 \mathrm{eV}$.


Figure 13. XPS spectra for $\mathrm{MoS}_{2}$-CE. (A) Mo 3d region, experimental data (…), fitting envelope (gold), $\mathrm{Mo}^{\mathrm{A}} \mathrm{S}_{\mathrm{n}}(\mathrm{green}), \mathrm{Mo}^{\mathrm{B}} \mathrm{O}_{\mathrm{a}} \mathrm{S}_{\mathrm{b}}(\mathrm{cyan}), \mathrm{MoO}_{3}$ (magenta), $\mathrm{S}_{2}{ }^{2-}$ 2s (red), $\mathrm{S}^{2-}$ 2s (blue). (B) S 2p region, experimental data (…), fitting envelope (gold), $\mathrm{S}_{2}{ }^{2-}$ (red), $\mathrm{S}^{2-}$ (blue).

because the spin-orbit splitting of core levels is constant for a specific orbital of the element. The full width at half-maximum (fwhm) was fixed among all amorphous materials; this fwhm is bigger than its counterpart in crystalline $\mathrm{MoS}_{2}$, probably due to the amorphous nature of the materials. An exception was made to the fwhm of the elemental $S(0)$ component; that fwhm needs to be small for a satisfactory fitting.

Figure 12 shows the XPS data of a $\mathrm{MoS}_{3}-\mathrm{AE}$ film. In the Mo $3 \mathrm{~d}$ spectrum, a main doublet with a $3 \mathrm{~d}_{5 / 2}$ binding energy of $229.8 \mathrm{eV}$ is found. This doublet is attributed to the $\mathrm{Mo}^{\mathrm{IV}}$ ion in $\mathrm{MoS}_{3} .{ }^{35}$ Next to the Mo $3 \mathrm{~d}$ region is the S 2 s region. Three singlets are found, two for the sulfide/disulfide ions and the other for elemental sulfur. The area of the latter singlet is about $15 \%$ of the area of the other singlets. Likewise, three doublets were used to fit the $S 2 \mathrm{p}$ spectrum. The relative areas of these doublets were fixed according to the ratios observed in the $\mathrm{S} 2 \mathrm{~s}$ region. The $S 2 p_{3 / 2}$ components have binding energies of 163.6, 162.9 , and $162.0 \mathrm{eV}$, corresponding to elemental $\mathrm{S}(0)$, bridging $\mathrm{S}_{2}{ }^{2-}$, and terminal $\mathrm{S}^{2-}$, respectively. ${ }^{35-37}$ As terminal $\mathrm{S}^{2-}$ has a similar binding energy to terminal $\mathrm{S}_{2}{ }^{2-}$, the relative intensities of the peaks at 162.9 and $162.0 \mathrm{eV}$ might not be used to accurately deduce the $\mathrm{S}_{2}{ }^{2-} / \mathrm{S}^{2-}$ ratio in the sample. ${ }^{35}$ The shapes and binding energies of Mo and S XPS peaks of this film are similar to those of amorphous $\mathrm{MoS}_{3}$ particles and films. ${ }^{35,38}$ The Mo/S ratio is 1:3.6. Therefore, the XPS data point to a $\mathrm{MoS}_{3}$ film contaminated with some residual elemental sulfur, as suggested by eq 1 .

Figure 13 shows the XPS data of a $\mathrm{MoS}_{2}-\mathrm{CE}$ film. The Mo $3 \mathrm{~d}$ spectrum is best fit with three doublets. The doublet with a Mo $3 d_{5 / 2}$ of $232.7 \mathrm{eV}$ is due to the $\mathrm{Mo}{ }^{\mathrm{VI}}$ ion in $\mathrm{MoO}_{3}$. Thus, 
the film contains an appreciable amount of $\mathrm{MoO}_{3}$ (about 19\% of total Mo; see Figure S5 for O 1s XPS spectrum). This $\mathrm{MoO}_{3}$ might come from air oxidation of the film during deposition, or during the sample transfer process for XPS measurement. It was reported that $\mathrm{MoS}_{2}$ on $\mathrm{Au}(111)$ was not prone to air oxidation. ${ }^{39}$ However, in the $\mathrm{MoS}_{2}$ - CE film, $\mathrm{OH}^{-}$is produced during reductive deposition (eq 3 ), which might facilitate the formation of $\mathrm{MoO}_{3}$. The other two doublets have a $3 \mathrm{~d}_{5 / 2}$ binding energy of 229.3 and $230.5 \mathrm{eV}$. The doublet with the lower binding energy is attributed to $\mathrm{Mo}^{\mathrm{IV}}$ as in $\mathrm{MoS}_{2}$ or $\mathrm{MoS}_{3}$. The doublet with the higher energy, however, might be attributed to a Mo ion in molybdenum oxysulfides according to a previous XPS study. ${ }^{40}$ The S $2 \mathrm{p}$ spectrum indicates two types of sulfide ions, with a $2 \mathrm{p}_{3 / 2}$ binding energy of 162.0 and 163.4 $\mathrm{eV}$. The S 2 s spectrum was also fitted with two doublets, with the same relative intensities for the two sulfide ions observed in the $S 2 p$ spectrum. No signal due to elemental $S$ was necessary for the fitting of the $S$ spectra. The Mo/S ratio is 1:2.1. The XPS data of the $\mathrm{MoS}_{2}$-CE film are distinct from those of the $\mathrm{MoS}_{3}$-AE film and $\mathrm{MoS}_{2}$ microcrystals (see Table 1 for a

\section{Table 1. Representative XPS Data ${ }^{a}$}

\begin{tabular}{|c|c|c|c|c|c|c|}
\hline material & $\begin{array}{l}\mathrm{Mo}^{1} \\
3 \mathrm{~d}_{5 / 2} \\
(\mathrm{eV})\end{array}$ & $\begin{array}{l}\mathrm{Mo}^{2} \\
3 \mathrm{~d}_{5 / 2} \\
(\mathrm{eV})\end{array}$ & $\begin{array}{l}\mathrm{S}_{2}{ }^{2-} \\
2 \mathrm{p}_{3 / 2} \\
(\mathrm{eV})\end{array}$ & $\begin{array}{c}\mathrm{S}^{2-} 2 \mathrm{p}_{3 / 2} \\
(\mathrm{eV})^{b^{2}}\end{array}$ & $\begin{array}{c}\mathrm{S}^{0} 2 \mathrm{p}_{3 / 2} \\
(\mathrm{eV})\end{array}$ & $\begin{array}{c}\mathrm{Mo} / \mathrm{S} \\
\text { ratio }\end{array}$ \\
\hline $\begin{array}{l}\text { crystalline } \\
\mathrm{MoS}_{2}\end{array}$ & 229.5 & & & $\begin{array}{l}162.4 \\
(100 \%)\end{array}$ & & $1: 1.9$ \\
\hline $\mathrm{MoS}_{3}-\mathrm{AE}$ & 229.8 & & $\begin{array}{l}162.9 \\
(59 \%)\end{array}$ & $\begin{array}{l}162.0 \\
(26 \%)\end{array}$ & $\begin{array}{l}163.6 \\
(15 \%)\end{array}$ & $1: 3.6$ \\
\hline $\mathrm{MoS}_{2}-\mathrm{CE}$ & 229.3 & 230.5 & $\begin{array}{c}163.4 \\
(27 \%)\end{array}$ & $\begin{array}{l}162.0 \\
(73 \%)\end{array}$ & & $1: 2.1$ \\
\hline $\begin{array}{l}\mathrm{MoS}_{3}-\mathrm{AE} \\
\text { after acid } \\
\text { wash }\end{array}$ & 229.7 & 230.9 & $\begin{array}{l}163.2 \\
(60 \%)\end{array}$ & $\begin{array}{l}162.0 \\
(40 \%)\end{array}$ & & $1: 3.2$ \\
\hline $\begin{array}{l}\mathrm{MoS}_{3}-\mathrm{AE} \\
\text { after } \\
\text { activation }\end{array}$ & 229.5 & 230.7 & $\begin{array}{l}163.1 \\
(27 \%)\end{array}$ & $\begin{array}{l}162.0 \\
(73 \%)\end{array}$ & & $1: 2.0$ \\
\hline
\end{tabular}

${ }^{a}$ fwhm is fixed for Mo, $\mathrm{S}^{2-}$, and $\mathrm{S}_{2}{ }^{2-}$ in all amorphous films. ${ }^{b}$ This doublet may contain contributions from terminal $\mathrm{S}_{2}{ }^{2-}$ as well.

comparison). They indicate a complex composition and structure of the $\mathrm{MoS}_{2}$-CE film: there are several types of Mo ions and at least two different sulfide ions. While the ratio of Mo to S suggests a composition close to $\mathrm{MoS}_{2}$, this film has a different spectroscopic property than crystalline $\mathrm{MoS}_{2}$.

Since the EQCM study indicates that the molybdenum sulfide films prepared by potential cycling are mixtures of
$\mathrm{MoS}_{3}-\mathrm{AE}$ and $\mathrm{MoS}_{2}-\mathrm{CE}$, their XPS data are not discussed in detail. It is sufficient to mention that the XPS data indeed confirm the conclusion from the EQCM study. The surface of a film prepared by potential cycling between 0.7 and $-0.4 \mathrm{~V}$ resembles that of a $\mathrm{MoS}_{3}-\mathrm{AE}$ film except that no elemental $\mathrm{S}$ is present owing to corrosion by eq 2 (Figure S6, SI); the surface of a film prepared by potential cycling between -0.4 and $0.7 \mathrm{~V}$ resembles that of a $\mathrm{MoS}_{2}$-CE film (Figure S6, SI).

2.2. Activation of $\mathrm{MoS}_{3}$ Film and Nature of the Active Catalyst. An activation process was earlier identified for certain molybdenum sulfide films. ${ }^{29}$ This activation process is marked by a reduction of freshly prepared films at potentials just positive of those of HER. The reduction is most significant for the $\mathrm{MoS}_{3}$-AE film but is negligible for the $\mathrm{MoS}_{2}$-CE film. We had proposed that this reduction transformed a $\mathrm{MoS}_{3}$ film into the active form that has a composition close to $\mathrm{MoS}_{2}$ but has a structure very different from crystalline $\mathrm{MoS}_{2}$. This active film is similar to the $\mathrm{MoS}_{2}$-CE film which does not require activation. We had described these active films as "amorphous $\mathrm{MoS}_{2}$ films" because their Mo/S ratio is close to 2 and because their XPS spectra resemble that of $\mathrm{MoS}_{2}$ microcrystals at a first glance. ${ }^{29}$ Given a large body of contemporary work on the catalytic activity of crystalline $\mathrm{MoS}_{2}$ nanoparticles, the term "amorphous $\mathrm{MoS}_{2}$ " is not informative and even confusing as it does not emphasize enough the difference between the two species. To better understand the activation process, we used EQCM to measure the change of the weight of a $\mathrm{MoS}_{3}-\mathrm{AE}$ film during the activation process. To better describe the nature of the active catalyst, we fit its XPS data using the same procedure as in section 2.1.

$\mathrm{A} \mathrm{MoS}_{3}$-AE film with a loading of $18.4 \mu \mathrm{g} \cdot \mathrm{cm}^{-2}$ was first deposited on the working electrode of EQCM. When the electrolyte solution was changed to $1.0 \mathrm{M} \mathrm{H}_{2} \mathrm{SO}_{4}$, the vibrating frequency of the quartz crystal increased, corresponding to a weight loss of about $7 \%\left(1.3 \mu \mathrm{g} \cdot \mathrm{cm}^{-2}\right)$. We suspected that this was due to the removal of residual elemental $S$ by acid. XPS measurement confirmed this hypothesis. The singlet corresponding to the $2 \mathrm{~s}$ orbital of elemental $\mathrm{S}$ disappeared, and the $\mathrm{Mo} / \mathrm{S}$ ratio was 1:3.2 instead of 1:3.6 in a freshly prepared film (Figure 14). In the $S 2 p$ spectrum, the signal due to $S^{0}$ also disappeared. Moreover, the Mo $3 \mathrm{~d}$ spectrum had a significant change. Three doublets of Mo ions as in $\mathrm{MoO}_{3}, \mathrm{MoS}_{2} / \mathrm{MoS}_{3}$, and molybdenum oxysulfide were detected. The oxysulfide species might be formed by adsorption of oxygenic ions at the surface. Overall, the Mo $3 \mathrm{~d}$ spectrum of this acid-washed $\mathrm{MoS}_{3}$

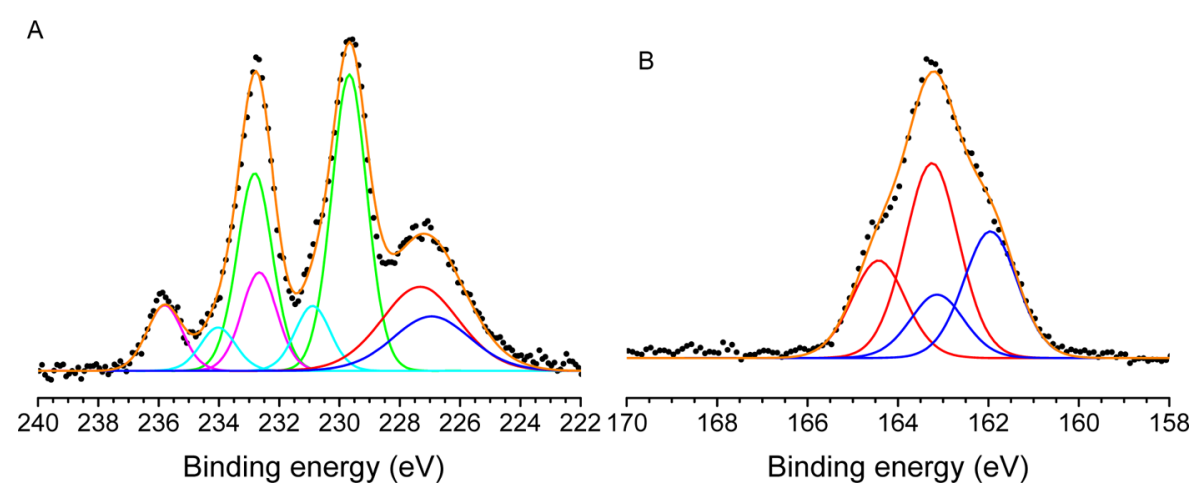

Figure 14. XPS spectra for $\mathrm{MoS}_{3}-\mathrm{AE}$ after immersion in a solution of $1 \mathrm{M} \mathrm{H}_{2} \mathrm{SO}_{4}$. (A) Mo 3d region, experimental data (…), fitting envelope (gold), $\mathrm{Mo}^{\mathrm{A}} \mathrm{S}_{\mathrm{n}}$ (green), $\mathrm{Mo}^{\mathrm{B}} \mathrm{O}_{\mathrm{a}} \mathrm{S}_{\mathrm{b}}$ (cyan), $\mathrm{MoO}_{3}$ (magenta), $\mathrm{S}_{2}{ }^{2-} 2 \mathrm{~s}$ (red), $\mathrm{S}^{2-} 2 \mathrm{~s}$ (blue). (B) S $2 \mathrm{p}$ region, experimental data (…), fitting envelope (gold), $\mathrm{S}_{2}^{2-}$ (red), $\mathrm{S}^{2-}$ (blue). 
film is similar to its counterpart in $\mathrm{MoS}_{2}-\mathrm{CE}$, which indicates that the Mo $3 \mathrm{~d}$ XPS spectrum is not suited for differentiating molybdenum sulfides in various forms. The $S 2 \mathrm{p}$ xps spectrum, however, seems to fit this role.

The acid-washed $\mathrm{MoS}_{3}$ film was then subjected to a linear potential sweep. A significant mass decrease was observed from 0.005 to $-0.20 \mathrm{~V}$ (Figure 15). Below $-0.20 \mathrm{~V}$, HER became

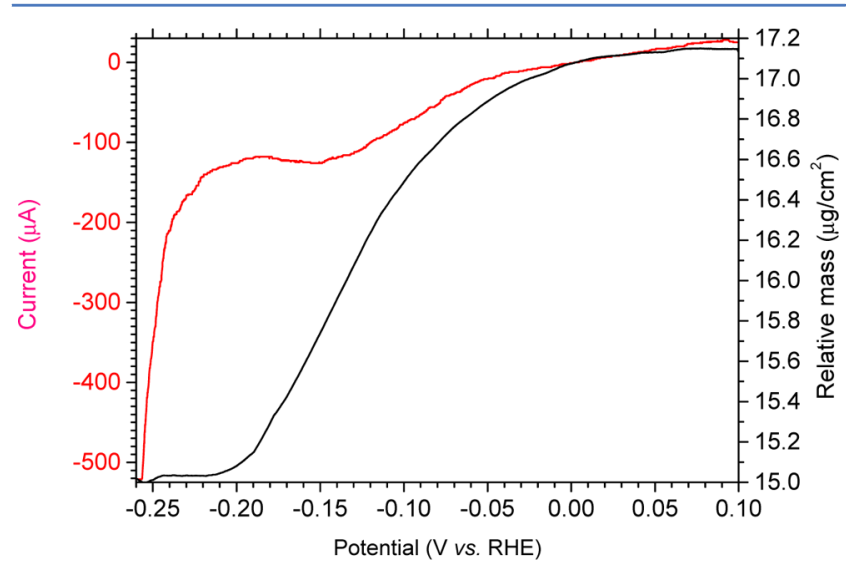

Figure 15. The mass change during the activation of a $\mathrm{MoS}_{3}$ film in the first linear sweep scan. Au substrate, $\mathrm{H}_{2} \mathrm{SO}_{4}$ electrolyte (1 M), scan rate $5 \mathrm{mV} / \mathrm{s}$.

evident, but the mass stayed nearly constant. The region where the mass decreased parallels the region of activation. The total mass loss, of about $2.5 \mu \mathrm{g} \cdot \mathrm{cm}^{-2}$, amounted to $15 \%$ of the $\mathrm{MoS}_{3}$ film before activation. Converting $\mathrm{MoS}_{3}$ into $\mathrm{MoS}_{2}$ will result in a $17 \%$ loss of the original weight. Therefore, the mass decrease during the activation is consistent with a removal of slightly less than 1 equivalent of $\mathrm{S}$ from $\mathrm{MoS}_{3}$.

Figure 16 shows the XPS data of the activated species from the $\mathrm{MoS}_{3}-\mathrm{AE}$ film. The spectra are similar to those of $\mathrm{MoS}_{2}-\mathrm{CE}$ film. In the Mo $3 \mathrm{~d}$ spectrum, in addition to the peak corresponding to $\mathrm{MoO}_{3}$, two doublets due to $\mathrm{Mo}^{\mathrm{IV}}$ ions were observed. Likewise, two doublets due to sulfide ions were observed in the $S 2 \mathrm{p}$ spectrum. The Mo/S ratio was 1:2. The relative intensity of the peaks due to $S_{2}{ }^{2-}$ and $S^{2-}$ in the activated film is identical to that in the $\mathrm{MoS}_{2}-\mathrm{CE}$ film; it is 27:73.

Table 1 lists the Mo $3 \mathrm{~d}$ and $\mathrm{S} 2 \mathrm{p}$ binding energies and the $\mathrm{Mo} / \mathrm{S}$ ratios of representative films; Table S1, Supporting Information, lists their $S 2$ s binding energies. The data indicate that after activation, $\mathrm{MoS}_{3}$ - $\mathrm{AE}$ becomes equivalent to $\mathrm{MoS}_{2}-\mathrm{CE}$ in spectroscopic property and in catalytic activity (see above, section 1.6). The active catalyst in all amorphous molybdenum sulfide films, regardless of how they are produced initially, is the same. We label this species as $\mathrm{MoS}_{2+x}$; it has a Mo/S ratio close to 2 and a characteristic S 2p XPS spectrum as in Figure 13B and Figure 16B. The relative intensity of the $S$ XPS peaks due to the $\mathrm{S}_{2}{ }^{2-} / \mathrm{S}^{2-}$ ratio is close to $3: 7$.

2.3. Reconciliation with Related Studies. The preceding EQCM and XPS studies allow us to rectify our previous proposal concerning the nature of the active species in amorphous molybdenum sulfide films. We had described the active species as "amorphous $\mathrm{MoS}_{2}$ " based on a visual inspection of XPS data. The more precise fitting described herein shows that the S 2 p XPS spectrum of the active catalyst is distinct from crystalline $\mathrm{MoS}_{2}$ as it contains two sulfide doublets rather than one. The notion " $\mathrm{MoS}_{2+x}$ " then seems more appropriate. We and others developed a wet chemical method to produce amorphous $\mathrm{MoS}_{3}$ particles, which is an active precatalyst for HER. ${ }^{20,27}$ We initially suggested that the active species, reduced from $\mathrm{MoS}_{3}$ particles, was chemically different from "amorphous $\mathrm{MoS}_{2}$ " as its S 2p XPS spectrum consisted of two sulfide doublets. Reexamination of the two XPS spectra now indicates that they are nearly identical. Thus, the active catalyst from amorphous $\mathrm{MoS}_{3}$ particles is the same " $\mathrm{MoS}_{2+x}$ " species. A large number of recent reports show that amorphous molybdenum sulfides, despite the variance in their methods of preparation, exhibit similarly high HER activity as electrocatalysts or photoelectrocatalysts. While rigorous fitting of XPS spectra is not done on all materials, the XPS spectra appear similar. We hypothesize that the $\mathrm{MoS}_{2+x}$ species is the same active catalyst for all of these materials.

\section{CONCLUSION}

The EQCM study reveals the growth of amorphous molybdenum sulfide films under various electrochemical deposition conditions. If potential cycling is employed as the deposition method, the film is grown by periodic oxidative deposition, reductive corrosion, and reductive deposition according to eqs $1-3$. The growth rate depends on the concentration of film precursor $\left[\mathrm{MoS}_{4}\right]^{2-}$; a higher concentration results in a faster growth. The growth rate also depends on the potential window of deposition, in a nonlinear manner, due to the interplay of corrosion and reductive deposition. A film can also be deposited by potentiostatic oxidation or reduction, according to eq 1 or eq 3 . The rate of film growth follows the order of potentiostatic oxidation (anodic

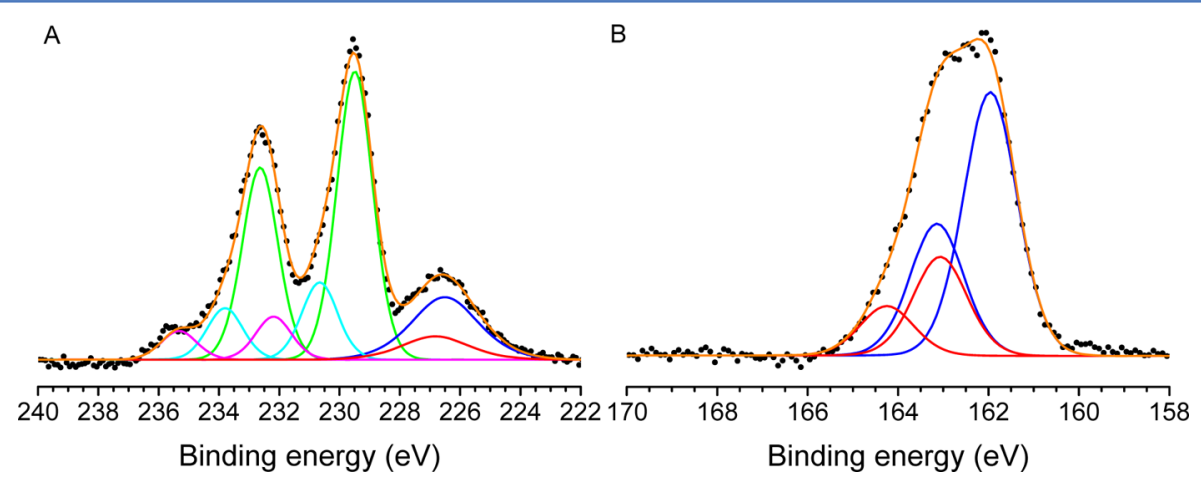

Figure 16. XPS spectra for $\mathrm{MoS}_{3}-\mathrm{AE}$ after activation. (A) Mo 3d region, experimental data (…), fitting envelope (gold), Mo ${ }^{\mathrm{A}} \mathrm{S}_{\mathrm{n}}(\mathrm{green}), \mathrm{Mo}^{\mathrm{B}} \mathrm{O}_{\mathrm{a}} \mathrm{S}_{\mathrm{b}}$ (cyan), $\mathrm{MoO}_{3}$ (magenta), $\mathrm{S}_{2}{ }^{2-} 2 \mathrm{~s}$ (red), $\mathrm{S}^{2-}$ s (blue). (B) S 2p region, experimental data (…), fitting envelope (gold), $\mathrm{S}_{2}^{2-}$ (red), $\mathrm{S}^{2-}$ (blue). 
electrolysis), potential cycling, and potentiostatic reduction (cathodic electrolysis). All films, regardless of how they were electrodeposited, exhibit similar HER activity on a per mass basis. Anodic electrolysis can be considered the fastest method to produce a catalytically active film. In the range of 20 to 200 $\mu \mathrm{g} / \mathrm{cm}_{2}$, the HER activity scales with catalyst loading. At a loading of $200 \mu \mathrm{g} / \mathrm{cm}_{2}$, the current density is $20 \mathrm{~mA} / \mathrm{cm}^{2}$ at an overpotential of ca. $170 \mathrm{mV}$; this activity can be considered the benchmark for amorphous molybdenum sulfide films. As proposed before, the higher activity of the amorphous $\mathrm{MoS}_{2+x}$ catalyst, compared with many other $\mathrm{MoS}_{2}$ nanoparticles, is likely due to a higher amount of unsaturated Mo and $S$ sites in this material. ${ }^{11,29}$

The XPS study reveals the composition of various molybdenum sulfide films. The film produced by anodic electrolysis $\left(\mathrm{MoS}_{3}-\mathrm{AE}\right)$ is amorphous $\mathrm{MoS}_{3}$ plus some residual $\mathrm{S}$. The film produced by cathodic electrolysis $\left(\mathrm{MoS}_{2}-\mathrm{CE}\right)$ has a Mo:S ratio close to $1: 2$ but a different chemical environment than crystalline $\mathrm{MoS}_{2}$. The films produced by potential cycling are mixtures of $\mathrm{MoS}_{3}-\mathrm{AE}$ and $\mathrm{MoS}_{2}$-CE films.

Most amorphous molybdenum sulfide films undergo a reductive activation process prior to hydrogen evolution. The activation is most pronounced for the $\mathrm{MoS}_{3}-\mathrm{AE}$ film. The EQCM and XPS studies show that the residual S in the $\mathrm{MoS}_{3}$ AE film is first removed when the film is immersed in an acidic solution. The reductive activation, however, is associated with a significant weight loss and the transformation of $\mathrm{MoS}_{3}$ to the active species $\mathrm{MoS}_{2+x}$. The $\mathrm{MoS}_{2+x}$ species have nearly identical XPS spectra as the $\mathrm{MoS}_{2}$-CE film and have a Mo/S ratio close to $1: 2$. The relative intensity of the $S$ XPS peaks due to $S_{2}{ }^{2-} /$ $\mathrm{S}^{2-}$ ratio is close to 3:7. The $\mathrm{MoS}_{2}$-CE film, thus, is made of mostly $\mathrm{MoS}_{2+x}$, and no significant preactivation is required, in accordance with a previous study. It follows that the $\mathrm{MoS}_{2+x}$ species is the same active species in all amorphous molybdenum sulfide catalysts.

The $\mathrm{MoS}_{2+x}$ species should be distinguished from crystalline $\mathrm{MoS}_{2}$ owing to their different structure and XPS properties. While edge sites are the reactions sites for HER catalyzed by $\mathrm{MoS}_{2}$ nanoparticles, analogous defect sites are probably where HER occurs in amorphous molybdenum sulfide catalysts. More precise structural information such as local coordination geometries and bond distances necessitates structural characterization tools like X-ray absorption spectroscopy. ${ }^{41}$ The identification of the same active species $\left(\mathrm{MoS}_{2+x}\right)$ in all amorphous catalysts, meanwhile, greatly facilitates such structural studies.

\section{ASSOCIATED CONTENT}

\section{S Supporting Information}

Experimental details and characterization data. This material is available free of charge via the Internet at http://pubs.acs.org.

\section{AUTHOR INFORMATION}

\section{Corresponding Author}

*E-mail: xile.hu@epfl.ch.

\section{Notes}

The authors declare no competing financial interest.

\section{ACKNOWLEDGMENTS}

This work is supported by a starting grant from the European Research Council (no. 257096). We thank Nicolas Xanthopoulos (EPFL) for XPS measurements.

\section{REFERENCES}

(1) Cook, T. R.; Dogutan, D. K.; Reece, S. Y.; Surendranath, Y.; Teets, T. S.; Nocera, D. G. Chem. Rev. 2010, 110, 6474-6502.

(2) Walter, M. G.; Warren, E. L.; McKone, J. R.; Boettcher, S. W.; Mi, Q. X.; Santori, E. A.; Lewis, N. S. Chem. Rev. 2010, 110, 6446-6473.

(3) Reece, S. Y.; Hamel, J. A.; Sung, K.; Jarvi, T. D.; Esswein, A. J.; Pijpers, J. J. H.; Nocera, D. G. Science 2011, 334, 645-648.

(4) Du, P. W.; Eisenberg, R. Energy Environ. Sci. 2012, 5, 6012-6021.

(5) Le Goff, A.; Artero, V.; Jousselme, B.; Tran, P. D.; Guillet, N.; Metaye, R.; Fihri, A.; Palacin, S.; Fontecave, M. Science 2009, 326, 1384-1387.

(6) Helm, M. L.; Stewart, M. P.; Bullock, R. M.; DuBois, M. R.; DuBois, D. L. Science 2011, 333, 863-866.

(7) Chen, W. F.; Wang, C. H.; Sasaki, K.; Marinkovic, N.; Xu, W.; Muckerman, J. T.; Zhu, Y.; Adzic, R. R. Energy Environ. Sci. 2013, 6, 943-951.

(8) Karunadasa, H. I.; Montalvo, E.; Sun, Y. J.; Majda, M.; Long, J. R.; Chang, C. J. Science 2012, 335, 698-702.

(9) McKone, J. R.; Sadtler, B. F.; Werlang, C. A.; Lewis, N. S.; Gray, H. B. ACS Catal. 2013, 3, 166-169.

(10) Danilovic, N.; Subbaraman, R.; Strmcnik, D.; Chang, K. C.; Paulikas, A. P.; Stamenkovic, V. R.; Markovic, N. M. Angew. Chem., Int. Ed. 2012, 51, 12495-12498.

(11) Merki, D.; Hu, X. L. Energy Environ. Sci. 2011, 4, 3878-3888.

(12) Laursen, A. B.; Kegnaes, S.; Dahl, S.; Chorkendorff, I. Energy Environ. Sci. 2012, 5, 5577-5591.

(13) Tributsch, H.; Bennett, J. C. J. Electroanal. Chem. 1977, 81, 97111.

(14) Tributsch, H. Ber. Bunsen-Ges. 1977, 81, 361-369.

(15) Hinnemann, B.; Moses, P. G.; Bonde, J.; Jorgensen, K. P.; Nielsen, J. H.; Horch, S.; Chorkendorff, I.; Norskov, J. K. J. Am. Chem. Soc. 2005, 127, 5308-5309.

(16) Jaramillo, T. F.; Jorgensen, K. P.; Bonde, J.; Nielsen, J. H.; Horch, S.; Chorkendorff, I. Science 2007, 317, 100-102.

(17) Bonde, J.; Moses, P. G.; Jaramillo, T. F.; Norskov, J. K.; Chorkendorff, I. Faraday Discuss. 2008, 140, 219-231.

(18) Chen, Z. B.; Cummins, D.; Reinecke, B. N.; Clark, E.; Sunkara, M. K.; Jaramillo, T. F. Nano Lett. 2011, 11, 4168-4175.

(19) Kibsgaard, J.; Chen, Z. B.; Reinecke, B. N.; Jaramillo, T. F. Nat. Mater. 2012, 11, 963-969.

(20) Benck, J. D.; Chen, Z. B.; Kuritzky, L. Y.; Forman, A. J.; Jaramillo, T. F. ACS Catal. 2012, 2, 1916-1923.

(21) Kim, J.; Byun, S.; Smith, A. J.; Yu, J.; Huang, J. X. J. Phys. Chem. Lett. 2013, 4, 1227-1232.

(22) Chang, Y. H.; Lin, C. T.; Chen, T. Y.; Hsu, C. L.; Lee, Y. H.; Zhang, W. J.; Wei, K. H.; Li, L. J. Adv. Mater. 2013, 25, 756-760.

(23) Laursen, A. B.; Vesborg, P. C. K.; Chorkendorff, I. Chem. Commun. 2013, 49, 4965-4967.

(24) Wang, T. Y.; Liu, L.; Zhu, Z. W.; Papakonstantinou, P.; Hu, J. B.; Liu, H. Y.; Li, M. X. Energy Environ. Sci. 2013, 6, 625-633.

(25) Liao, L.; Zhu, J.; Bian, X. J.; Zhu, L. N.; Scanlon, M. D.; Girault, H. H.; Liu, B. H. Adv. Funct. Mater. 2012, DOI: 10.1002/ adfm.201300318.

(26) Bian, X. J.; Zhu, J.; Liao, L.; Scanlon, M. D.; Ge, P. Y.; Ji, C.; Girault, H. H.; Liu, B. H. Electrochem. Commun. 2012, 22, 128-132.

(27) Vrubel, H.; Merki, D.; Hu, X. L. Energy Environ. Sci. 2012, 5, 6136-6144.

(28) Merki, D.; Vrubel, H.; Rovelli, L.; Fierro, S.; Hu, X. L. Chem. Sci. 2012, 3, 2515-2525.

(29) Merki, D.; Fierro, S.; Vrubel, H.; Hu, X. L. Chem. Sci. 2011, 2, $1262-1267$.

(30) Seger, B.; Laursen, A. B.; Vesborg, P. C. K.; Pedersen, T.; Hansen, O.; Dahl, S.; Chorkendorff, I. Angew. Chem., Int. Ed. 2012, 51, 9128-9131.

(31) Belanger, D.; Laperriere, G.; Marsan, B. J. Electroanal. Chem. 1993, 347, 165-183.

(32) Ponomarez, E. A.; Neumann-Spallart, M.; Hodes, G.; LevyClement, C. Thin Solid Films 1996, 280, 86-89. 
(33) Weber, T.; Muijsers, J. C.; vanWolput, H.; Verhagen, C. P. J.; Niemantsverdriet, J. W. J. Phys. Chem. 1996, 100, 14144-14150.

(34) Muijsers, J. C.; Weber, T.; vanHardeveld, R. M.; Zandbergen, H. W.; Niemantsverdriet, J. W. J. Catal. 1995, 157, 698-705.

(35) Weber, T.; Muijsers, J. C.; Niemantsverdriet, J. W. J. Phys. Chem. 1995, 99, 9194-9200.

(36) Dejong, A. M.; Borg, H. J.; Vanijzendoorn, L. J.; Soudant, V.; Debeer, V. H. J.; Vanveen, J. A. R.; Niemantsverdriet, J. W. J. Phys. Chem. 1993, 97, 6477-6483.

(37) Kelemen, S. R.; George, G. N.; Gorbaty, M. L. Fuel 1990, 69, 939-944.

(38) Belanger, D.; Laperriere, G.; Girard, F.; Guay, D.; Tourillon, G. Chem. Mater. 1993, 5, 861-868.

(39) Nielsen, J. H.; Bech, L.; Nielsen, K.; Tison, Y.; Jorgensen, K. P.; Bonde, J. L.; Horch, S.; Jaramillo, T. F.; Chorkendorff, I. Surf. Sci. 2009, 603, 1182-1189.

(40) Benoist, L.; Gonbeau, D.; Pfisterguillouzo, G.; Schmidt, E.; Meunier, G.; Levasseur, A. Thin Solid Films 1995, 258, 110-114.

(41) Tang, M. L.; Grauer, D. C.; Lassalle-Kaiser, B.; Yachandra, V. K.; Amirav, L.; Long, J. R.; Yano, J.; Alivisatos, A. P. Angew. Chem., Int. Ed. 2011, 50, 10203-10207. 